\title{
Does Teachers' Educational and Professional Experience Impact on Teaching Strategies in Primary Education
}

\author{
Mifrah Ahmad \\ Deakin University
}

\begin{abstract}
Teachers' experience has undoubtedly evolved over a decade. Articulating teachers' perspectives and the thought-process of their personal educational and career experience and practice may influence their pedagogical approaches in their classrooms. Despite recent research on teachers' perspectives in digital technologies, their continuous experience of exploring, learning, planning, and training themselves advocates a connection towards various personal and growing experiences in practice that requires further research. Therefore, this paper explores primary school teachers' perspectives (Australia) towards the interrelation between their educational and career experience alongside its impact on their teaching practices. Theoretically underpinned with the theory of experience concepts (Dewey 1938), the phenomenological approach with the interpretivism paradigm is adopted to accept the subjective views of eleven primary school teachers through semi-structured interviews. Interpretive thematic analysis is adapted to ensure the depth of meaning of an individual's experience is rigorously investigated. Lastly, the paper demonstrates a broader discussion regarding the influence of 'experience' in teachers' learning acquisition and how it actively influences their teaching practice applied in primary education.
\end{abstract}

Keywords: teachers' belief, experience, teaching strategies, games, challenges, experiential learning, interpretivism, educational experience

\section{INTRODUCTION}

The teacher's position in the primary education level is highly distinguishing when compared with secondary and tertiary levels. Their practices, beliefs, education level, and the experiences they accumulate may or may not impact the teaching practices in the $21^{\text {st }}$-century classroom setting. A prominent article discussed the teachers' beliefs' about the limitations and potential possibilities of digital games in the classroom (Beavis et al., 2014, p. 569). It explored the "inevitably influence the decisions that they make about how, when, and for what specific purposes they will being these games in their classrooms" (p. 569). The authors identified the crucial position of teachers and the need to further expand on teachers' professional development at its highest priority. Another study questioned how teachers' beliefs may influence the intentions to implement change and how their insights may allow suggestions for professional development initiatives (Maass, 2011). With a thorough discussion on the mathematical model proposed by Maass (2011), the authors interviewed lower secondary teachers. The results suggested its contribution towards why modeling teachers' beliefs are still rare in day-in-day teaching. It seemed dominant that as the results related to the subject mathematics, their approach to modeling the teacher's belief on factors 
including phenomenon, context, casual conditions, strategies and consequences; seems limited in its application to other subjects.

Digital games as one of the learning tools have only emerged prominently in the 2000s years. Teachers mostly encountered games like board games or tangible games in their classrooms as compared to the current digitized classroom settings. Some studies have gathered teachers' views on how their current classroom setting is influenced by games. A relevant study was surveyed to obtain teachers' views on the approach of digital game-based learning (DGBL) within the curriculum in Scottish primary schools and discovered that $50 \%$ of teachers had used the technology while the other teachers did not (Razak, Connolly, \& Hainey, 2012). In addition, the obstacles faced by the teachers included: difficulty in assessing learning gain, lack of skills and training, time and curriculum constraints, difficulty in identifying a suitable game, and lack of PCs and technology. Previous studies suggest that teachers' professional development knowledge changes how they perceive the context and themselves, competencies (Schulman, 1986), and their classroom practices, including their beliefs (Schoenfeld, 2015). In addition, the nature of the subject and effective teaching practices vary immensely through teachers' beliefs (Stipek, Givvin, Salmon, \& MacGyvers, 2001). Henceforth, a significant interrelation between teachers' beliefs and day-to-day teaching routine appears prominent (Skott, 2001).

The position of teachers in primary school is highly challenging. As an educator, I strive to deliver the week's learning outcomes with creative approaches, real-life examples for learners to recognize. I intend to revert my experience to "when I was a student, what would I want my teachers to assist me with?" Experiencing the involvements within teachers as experts of their profession provides a flow or transfer of knowledge within the context. The author acknowledges that actions and consequences, learning and gaining knowledge - all vary amongst individuals. Teachers, in this case, remember what makes a positive or a negative impact in teaching the learning outcome while keeping their students engaged. With every teacher, there are similar experiences that can emerge. Astoundingly, the depth of understanding perspectives of teachers in primary schools has yet to be explored. Due to its subjectivity, the idea is to reduce the miscommunication between teachers' practices and educational institutions that have been evolving for decades. Although the gap stated is vast, this paper focuses on the impact of teachers' personal learning experiences and beliefs, how they were educated in their primary education, what influences their current pedagogies in the $21^{\text {st }}$ century, and how they adapt ever-evolving skills and learning outcomes.

Teachers' personal teaching and educational experience, inspirations, understanding their students, gaining the experience in their classroom, and explorative skills allow them to transform their personal experience continuously. To contextualize this paper, teachers are first-hand experienced in finding resources to assist them in delivering learning objectives/outcomes for tech-savvy generations. Each teacher with distinctive, unique experience is captured through semi-structured interviews through the concepts of the theory of experience by Dewey (1938) and Kolb's experiential cycle and andragogical principles. This paper reports on teachers' personal educational experiences and their impact on their role as teachers' perspectives and attitudes towards shifting pedagogies as digitization continues to reform teaching practices.

\section{RELATED LITERATURE REVIEW}

In relevance to understanding teachers' beliefs that potentially influence their career opportunities and classroom practices towards professional development has provided some initiatives in the study conducted in Germany (Maass, 2011). The results demonstrated two types of relationships between belief and categories that included context, consequences, strategies, causal conditions, and the phenomenon (which identified whether modeling or no modeling in class was observed during the classroom practice session). However, this study did a comprehensive analysis to suggest dialectic relationships between beliefs and classroom practices but claims that this understanding "is still rare in day-to-day teaching, despite decades of discussion in mathematics education." (p.583). Another study published teachers' beliefs aligning with the pedagogical practices and a thorough discussion on pedagogical approaches by proposing a framework called FRAMETEP (technology-enabled) (Prestridge \& de Aldama, 2016). The study showed evidence that 
there is a correlation between teachers' beliefs and approaches of pedagogies and the use of technology in the classroom. The case studies of teachers' perspectives were extracted from a large-scale project on using digital games in the classroom: Serious Play: Digital Games, Learning and Literacy for twenty First Century schooling (Beavis, Dezuanni, \& O'Mara, 2017). FRAMETEP is the most recent framework that demonstrates the beginning of revealing the interrelation between teachers' beliefs, their perspectives of using technology or games in the classroom, and the classifications of the way each teacher approaches the classroom lecture.

In recent years, the studies have prominently discussed the importance of perceptions of students and teachers in a classroom. The studies include perspectives of learning environment, engagement strategies, teacher's motivational strategies, or even the comparison of both students' and teachers' perceptions in viewing the classroom context. The differences between the students' and teachers' views of a learning environment were humongous, and this requires detailed attention by researchers to critically analyze position both teachers and students as the prominent actors of an optimized learning environment (Könings, Seidel, Brand-Gruwel, \& van Merriënboer, 2014). Another study explored how primary school children reacted to the inclusion and exclusion of their peers during game playing in NSW (Australia) through observational and interactional interviews (Varea \& Ndhlovu, 2017) and reported that utilizing exclusions allows students to maintain their friendship relationships (the social aspects) and implied that the strategies adopted by adults to promoting inclusions amongst children vary according to the choices of play.

\section{THEORETICAL AND CONCEPTUAL RELEVANCE OF DATA ANALYSIS AND INTERPRETATION}

A brief explanation of the theory used in this study and the data analysis method is presented in the following sections.

\section{Theoretical Framework}

The conceptual and theoretical framework/lens adopted and presented in this paper relates to John Dewey's theory of experience concepts (1938): growth of experience, purpose, and continuity. As these concepts were relevant to the epistemology and ontology of the research, constructivism belief is situated as the paradigm to allow the construction of new knowledge which welcomes the subjectivity of individual experiences. The growth of experience represents the ways in which individuals grow in their career, experience the everyday activities to gain knowledge, learn to achieve their goals, sustain their understanding of the phenomenon - and continue to grow in their experience (Dewey, 1938). Along with the aspect 'growth' driven by one's desire to formulate a 'purpose' that reverts to the growth of experience with the intelligence of one's mind. Intuitively, adult learning occurs through a particular interest that embodies their personal histories, how they envision the world, and what they want to do or what they can do.

In this context, the adults whose learning methods are a combination of work and studying or theoretical and practical exposures are highly familiar and productive in their expertise. The purpose is simple when a desirable quality "... which identifies freedom with power to frame purposes and execute or carry into effect purposes so framed. Such freedom is, in turn, identical with self-control; for the formation of purposes and the organization of means them are the work of intelligence" (Dewey, 1938, p.67). Dewey's description of an actual purpose is that it begins with an impulse. It is always equipped with "end-view" which is involving "the foresight of the consequences that may result from acting upon that impulse" (1938, p.67). The teachers create their own meaning and reflect through their actions to gather knowledge that demonstrates its relevance to forming a 'learning experience' for learners in the classroom context. Hence, deriving an enriched experience that shows an individualized learning growth, learning by doing, and adapting the current requirements to provide an experience to students completes the cycle of experiential learning.

The principle of continuity is where each experience is taken from the past and affects the future experience of the individual. At the same time, interaction is referred to the situational and teacher's 
influence on students' experience. He believes that the elements of interaction and the situation in which they occur are "inseparable from each other" (1938, p. 41). Some challenges may be encountered despite the importance of experience, such as "that all experiences are genuinely or equally educative" (1938, p.13). This may lead to a 'miseducative' or a barrier to growing from the experience. Hence, the teachers must first comprehend the nature of human experience, stating that the effect judges the experience's value that this experience has on the individual's present and future, an individual's ability to contribute to society. This is placed directly to the idea of how teachers interact in their classrooms with every individuals' needs, to be able to support their cultural and social differences and to allow them to learn equally and freely. Therefore, experience, which may be enjoyable, may not contribute to personal growth or experience with no coherence to a situation that does not necessarily result in a cumulative learning foundation for future learning.

Theory of experience has been discussed and applied in many types of fields. The prominent Kolb's cyclic model (1984) of experiential theory built on the works of Dewey has provided its means in the field of education and educational games. As described above, experiential learning is simply defined by how learners experience a phenomenon and use that to facilitate learning. It has become a mutual ground for teachers and game designers attempting to integrate game-based learning with education (Appelman, 2005; Crawford, 1984; Gee, 2003; Kebritchi, 2008; Salen \& Zimmerman, 2004). As mentioned earlier, experiential learning is rooted in four basic principles (Dewey, 1938; Kolb, 1984):

- Learning involves participation in the real-world

- There are intimate relations between experience and education

- Understandings are derived from and modified through experience

- Meaningful learning consists of action and reflection. Experiential learning is also based on the belief that people learn best by doing.

The importance of how andragogy (education acquisition in adults) contributes to adult learning and processing information, defined as the theory of adult learning that details some of the ways adults learn distinctively than children (Knowles, 1980). A list of crucial assumptions to describe adult learning characteristics (see Figure 1) is adopted in the analysis to understand how adults learn and their ways of learning, gaining knowledge, and anticipating how learners learn (Knowles, Holton III, Swanson, \& Robinson, 2020).

\section{FIGURE 1 \\ ANDRAGOGICAL PRINCIPLES ADAPTED}

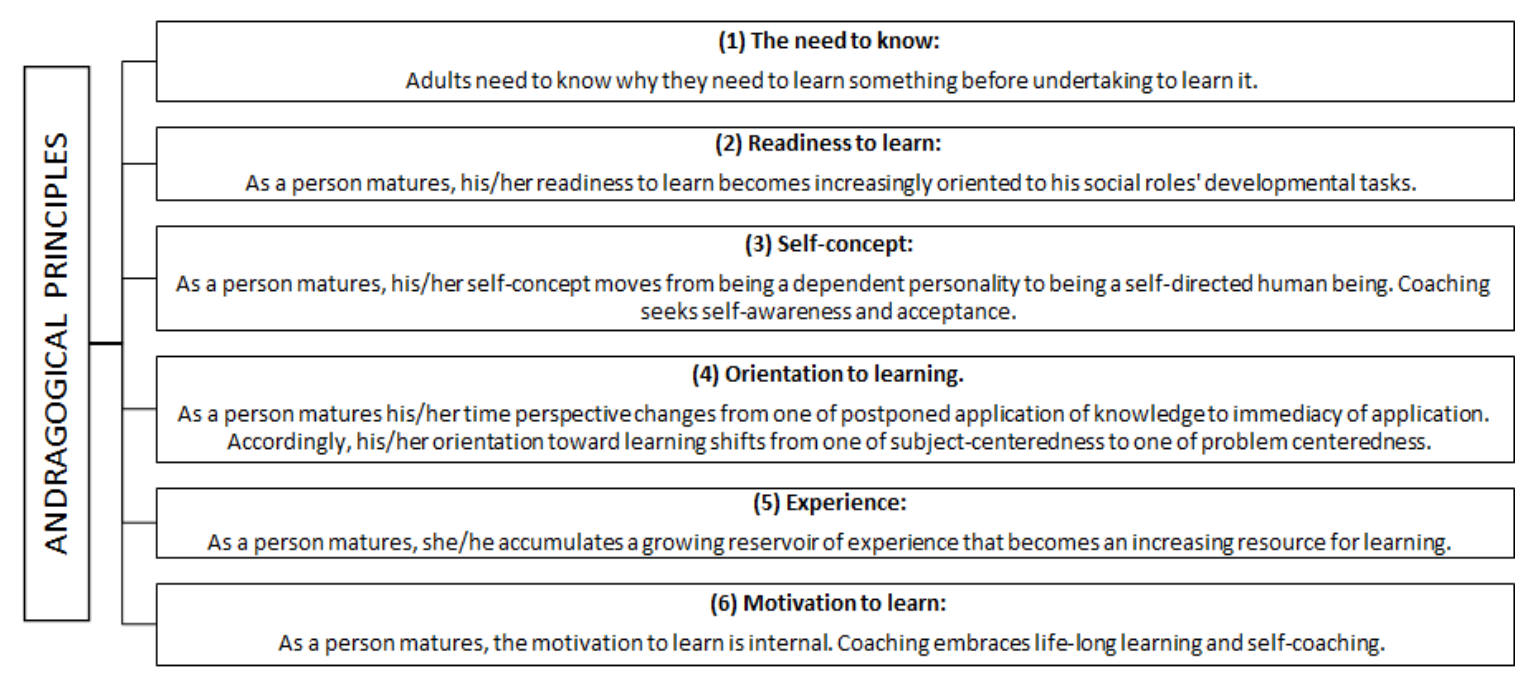

Knowles et al., 2020 


\section{Participant Recruitment Criteria, Data Collection Method, and Analysis}

Initially, the location was set to Victoria state, Australia; however, due to the pandemic, location expansion was determined to be a better approach. Thus, criterion and snowballing recruitment procedures were adopted over a period of time for semi-structured qualitative interviews with 11 primary school teachers in Australia (2020). The criteria set for the recruitment process are shown in Figure 2. The interviews were conceptualized through a phenomenological approach pursued by the researcher; the process of uncovering the essence of lived experiences may be described as a qualitative researcher identifying the phenomenon of human experience and then deriving a description representing the experience's very nature (Kafle, 2011). The essence should not be viewed as a vague idea but rather the ability to identify the meaning embodied in the lived experience (Merleau-Ponty \& Smith, 1962; Van Manen, 2016).

\section{FIGURE 2 PARTICIPANT RECRUITMENT CRITERIA IN THIS STUDY}

\begin{tabular}{|l|l|}
\hline Criteria & Details of Participants \\
\hline Location & Within Australia (Victoria, New South Wales and Queensland) \\
\hline Years of Experience & More than 5 years - 15 years \\
\hline Type of experience & $\begin{array}{l}\text { Teaching in classroom with games (digital/PC-based games) - } \\
\text { digital games, educational games, games }\end{array}$ \\
\hline $\begin{array}{c}\text { Types of audience/ } \\
\text { teaching grades }\end{array}$ & $\begin{array}{l}\text { Primary school years } \\
\text { Age: 9-11 students (Year 3-5) }\end{array}$ \\
\hline
\end{tabular}

\section{Data Analysis and Interpretation Approach}

With interviews recorded, the following step: transcribing. The transcriptions and time-stamp notes and analyzed the transcriptions and field notes, first, through immersion in the data corpus and hand-coding. Later, the data were further organized using NVIVO 10® software. This research adopted six (6) step thematic analysis approach (Braun \& Clarke, 2006, 2012), as shown (Figure 3). With theoretical and conceptual understanding, this analysis aims to allow teachers' perspectives, inspirational and motivational drivers, their experience (its growth, its continuity), and the way they contextualize their practices within the classroom to emerge (framing the purpose of using games as a learning tool). Second, the results are discussed through the interpretivism approach, where hermeneutic analysis is adopted to allow the subjectivity of the teacher's experience to flow through the experience, education, perspectives, and beliefs towards pedagogies. Lastly, correlating and critically discussing the results through the researcher's epistemology and ontology position and concepts of the theory of experience.

\section{FIGURE 3 \\ STEPS OF THEMATIC ANALYSIS ADOPTED}

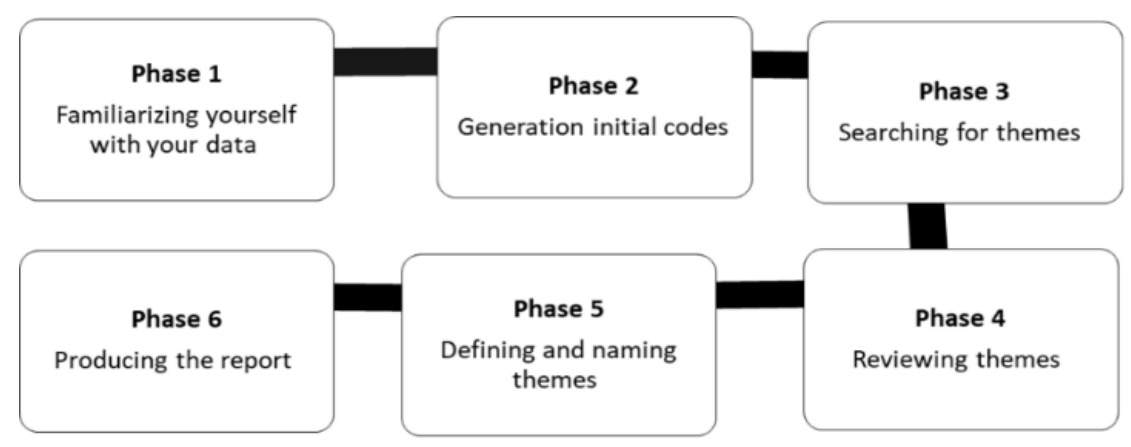

Braun \& Clarke, 2006 


\section{RESULTS DISCUSSION: INTERPRETIVE THEMATIC ANALYSIS}

This section discusses and interprets the emerging theme to demonstrate teachers' perspectives on how the impact of career changes, their personal education, and the current education and teaching standard differ. In addition, they are also questioned on how they perceive the difference in teaching primary education over the years of experience accumulated. The influence of teachers' educational experience, their learning acquisition (the process of gaining knowledge), and how they presume the knowledge is delivered to their students require deeper understanding towards designing games for learning. Their position as stakeholders in the game designing industry is highly crucial. The questions arise as: Does their past educational learning experience influence how they teach in the current classroom? Educators tend to believe that learning processes occur best when it is realistically presented to the learners. Primary education students are highly interactive, enjoy using various tools in the class, engage throughout multiple activities and provide constant feedback (the reaction to every tool changed). This is highly resourceful for teachers to learn, experience, reflect and modify the future teaching experience - for themselves and learners. As experiential learning is believed to have some impact on teacher's decisions towards the use of games in classrooms also includes other factors such as pedagogical approaches, the tools (physical/digital) used, their access to technologies (PCs, iPad, desktops, etc.,) or the time required to achieve curriculum goals. This theme is to understand whether various educational or career experiences influence their decisions in learning and experiencing challenges to teach in the classrooms. Please note that all names mentioned in the analysis are pseudonyms to abide by the consent forms signed by the participants.

\section{Central Theme: Teacher's Personal Educational and Learning Experience}

A commonality in this theme emerged with how 'passionate' they are to educate the younger generation and teach them in diverse ways, including challenging, entertaining and educative. Teachers are continuously learning to achieve the learning objectives required of the term with limited resources and tools (depending on whether the schools are able to afford PCs, iPad, etc.). Their preparation hours are limited where they explore, learn, evaluate, critique, and design the teaching session.

The majority of teachers interviewed for this study had a teaching experience of at least five years. As a researcher and an educator, data analysis showed how a teacher with 15 years of teaching experience compared to a teacher of 5 years. We, as educators, have to acknowledge the technological change in educational institutions for the past decade. The continuous transformation demonstrates the efforts of teachers as 'transformative.' Transformative learning refers to an occurrence of 'a shift' that is caused in an individual's perspective when a learning experience is altered. It is based on the idea that learning is (Mezirow, 1990a) "the process of making a new or revised interpretation of the meaning of an experience, which guides subsequent understanding, appreciation, and action." (p. 1). This links to andragogical principles and fosters critical reflections, relationships between different perspectives of learning, and the voices of moderators or instructors to achieve or share a common goal: achieving higher engagement and learning levels in their classroom. As clearly stated (Mezirow, 1990b), "Emancipatory education is an organized effort to help the learner challenge presuppositions, explore alternative perspectives, transform old ways of understanding, and act on new perspectives" (p.12). Their personal desires to "maintain excitement' in learning new tasks every day show a tremendous imitative of their perspectives and values in education.

The quotes below identified and explained how their primary education is compared to how they currently approach their teaching practices. Their experience in teaching, adopting new practices, the way they have encountered and learned - debriefed through their practices is highly essential. In education, we are aware of how individuals grasp personal experience in the field, but how it is adapted to changing learning environments can become prominent contextualized. Teachers have a constant urge to understand what their students are curious about and what is 'trending' to provide a realistic experience within the classroom with various learning tools to maintain students' engagement and motivation levels. 
[Serina]: "Look, I think, it's more about the belief and what kind of teacher you are. That determines how you pass experiences... when I started teaching about 20 years ago, I was in a general classroom setting. But in that situation, I always enjoyed it! There are lots of opportunities for children to really meaningfully understand what they are learning. There is a fix to knowing what they love! Learning what are they curious about? I'm really motivated towards deep learning \& purposefully contextualizing integrated learning. That's just who I am...."

[Jenna]: “...the beginning, I made sure there were lots of books, kids love various things that we did that really drove the learning! Practicing on various of software and managing Corporate Services...in my 20s because when I had my first year and I took my three class on 16 excursions! The average teacher does 4. Because it's experiential, kids can hang their creative, critical thinking hats on to learn deeply... It's just how I think drives their experience by my own pedagogical ideology and what I think is best for kids."

[Benzie]: “...Most people learn on the job, and I don't feel that strongly that way. I don't think my teacher training was that great. I'd say probably the most useful piece of tertiary education I've ever done was my philosophy degree purely because that taught me about the importance of different ways of thinking... to try to teach students something (what everybody's going to understand) in the same way is philosophical... philosophy helped me think about the same problem in various ways, and that's really useful for education. But in terms of teacher training, I wasn't all that impressed."

Teachers' recollection and reflection upon how they learned in their primary school and their comparison demonstrated the vast shift in teaching practices and pieces of training provided. The majority of teachers wished that their teachers did what they do in their classrooms now. Teachers seemed to position the learners as 'on-going work.' They believed that informing the students about what was going to be taught in the current session was highly crucial. One teacher believes that 'letting students explore the game for the first 10 minutes' shows their excitement of what they think we may learn - but we always need to give some instruction or information. Another teacher compared their own primary educational experience with how they teach now and explained that their own goal-oriented nature influences the way they approach their students. In the early 90s, when their experienced learning in their primary education, they encountered issues that they wished for students in their current classroom not to come across.

[Nikki]: "I'm very goal-oriented by just having a clear understanding of where I need to go to so that learning intention and success criteria, giving graded which I think is right, a purpose to the learning and understanding because going back to games in primary school, remember some activities we did random activities we did, and apparently they were actually linked to science. But it was never explained to us by the learning intention, the purpose, so the learning was completely mixed. So, apparently, that was pretty common for how I taught science back then as well. So, in the early 90s, and having structure and communicating allowing students a voice as well, I'm huge on that. Because I found that when I am not given an opportunity to talk about the learning or clarify my understanding of the learning, I get lost and confused, and frustrated. So, I think that's similar."

[Benzie]: “... I was in a gifted program when I was in grade six. As my teacher used to give us a double-sided A4, with all of the work that we had to do for the week...you could do that, whenever you want to. And if you got to finish then, you have free time. So, that was hugely influential on me [emphasis added], definitely in terms of what it takes to the idea of changing. I think a real failing in the education system is that it takes student voice completely out, and the mode of learning that you do at school has become artificial for 
lifelong learners now... It shouldn't force education [emphasis added]... "You must learn this because there's some boring old man at the front of the room telling you, "you have to learn it all!". Just like how the clocks turnover and now you[students] have to learn a completely unrelated subject with no real-life application! You learn in chunks of time that are appropriate for whatever you're learning, and however, your passions were feeling at the time...."

This also relates to the way andragogical principles of "need to know," "experience," and "motivation to learn" clearly (Figure 1). Regarding the relevance of discussion, the experiential learning concept of 'continuity and 'purpose' seems to be highly present in their perspectives. The teachers continuously learn various ways in which the learners can benefit and gain knowledge. Teachers' learning, their purpose drive them to frame through the learning outcomes/objectives of the subject. Framing the purpose shows the continuous aspect of allowing interactive, engaging, and motivating learning for the learners demonstrates their 'growth in experience.' This concludes that teachers' past educational and career experiences influence [to some extent] their thought-processes towards teaching in their classrooms. This is relevant to the study (Prestridge \& de Aldama, 2016), “...each teacher chooses a type of digital game based on her epistemic and pedagogical beliefs” (p.917).

Another teacher seemed to bring forward the experience from teaching secondary schools and being a banker. She felt that different age groups require different approaches to be understood. In addition, gaining skills at banking allowed her to find innovative approaches to teach math to individuals who dislike math in primary education. Another teacher agreed to how different career experiences assist her in current practice ad kept her updated with technological change over time. As mentioned in (Bigum, 2014), teachers own profound disciplinary knowledge that allows them to curate the curriculum effectively. Hence, this theme proves how it means to position teachers as producers of meaningful ways to practice in their classrooms. This demonstrated that relationships between individuals and objects, the experiences that become central to socially situated context - it can be a retail, a banking job, or even secondary level education; they are relevant to support teacher's self-concepts and growing reservoir of experience.

[Nikita]: Teaching secondary and being a banker - helps realize how different the age group of secondary to tertiary shows. Banking skills make me good with numbers! So, teaching math becomes so easy! And I tend to find all creative ways to make math enjoyable.

[Tia]: Oh, absolutely! Having worked in different places and roles allows you to gather skills and gain different perspectives that prepare you to teach or make you aware of new or old trends... because so I started teaching in 2003. And before I became a teacher, I was in the Navy. And I did electronics in the Navy, and prior to that, I worked in a local Ballarat hospital as a pathology technician ... all these skills helped me innovate my lessons!

With experienced teachers, we speculate that they have significant repertory from which they draw upon and be selective in an effective manner. Hence, expanding towards differentiated learning experiences. Dewey demonstrates the interplay between the curation of teachers' efforts and learning well. However, this theme attempts to illustrate the curation of teachers' educational, learning, and work/career experience, that assists teachers in providing a quality learning process for their students. For example, an individual preparing themselves to become a teacher and while doing so, working as a teacher-aid allowed them to understand 'what the teachers need to know, acknowledge, comprehend and gain technical skills.' Despite that, their experience attained from the retail, salesman and graphic designer, and technical support - all compiled into a fruitful belief that every experience is educative.

[Mary]:... I've been in education for a while because I was also a teacher-aid before, and while studying to be a teacher; I learned a lot during the teacher-aid job. My education 
major is in special education. And that's why also technology and gaming is interesting for me because it connects with all abilities [Emphasis added]. It's more inclusive; it takes on differentiation by using gaming. And before that, I've always had IT in my work, either retail, or being a salesman or graphic design, or tech support, that sort of thing... so technological change came naturally to me... I welcomed it!

\section{CONCLUSION OF INTERPRETIVE RESULTS}

Teachers' education and work experience are an accumulated source of skills they acquire to contribute to their teaching practices. Individual experiences of primary school teachers contribute to their current daily routine of decision-making processes: how what, and which teaching method (pedagogies) should be used to deliver the subject's learning outcomes. Therefore, it is crucial to understand teachers' experiences. It provides a continuous learning process, gaining knowledge respective to requirements, and delivering knowledge to children (younger generation) with pedagogical approaches that do not entirely connect with andragogical principles. Their desire to achieve 'satisfaction' in delivering learning is related to their personal inspirational and motivational drivers. Addressing pedagogical shifts, their technological 'savvy' skills, and the training facilitates teachers, impacting experiential learning. I observed that continuous growth in their educational experience somewhat enforces their ability to deliver knowledge more interactive and innovatively.

Lastly, with the interpretive results discussed above, the author would like to demonstrate the understanding of educational experience, teachers' career experience, and what factors impact their daily practices in Figure 4. To elaborate, Figure 4 visualizes how continuity represents the experience that teachers accumulate over time and 'learn' to grow their experience positively in the field of teaching. Meanwhile, their growth in experience and continuity occurs due to their sole purpose of educating students, maintaining learning outcomes through curriculum assigned, critically examining the learning tools (games, google classroom, etc.) that will motivate the learners in the $21^{\text {st }}$ century to cooperate, collaborate and critically think through the tasks. Their perspectives demonstrated that their own learning through their experience acknowledges somewhat the way they currently practice and adopt pedagogies. Consequently, this is interrelated with how their pedagogies have shifted over a decade, what are the limitations or challenges they face to adjust to the pedagogies they practice, and how limitations in resources, hardware, or software; hinder their teaching processes. Another noticeable aspect through interpretive results was the necessity of 'traditional' to 'progressive' classrooms. Dewey (1938) has engaged deeply with both types of education. However, this concern on how teachers categorize traditional and progressive education is being analyzed in the current research project. 


\section{FIGURE 4 \\ DEMONSTRATING THE FACTORS INFLUENCING TEACHER'S EDUCATIONAL EXPERIENCE AND WORK EXPERIENCE (THEIR TEACHING PRACTICES) OVER A DECADE}

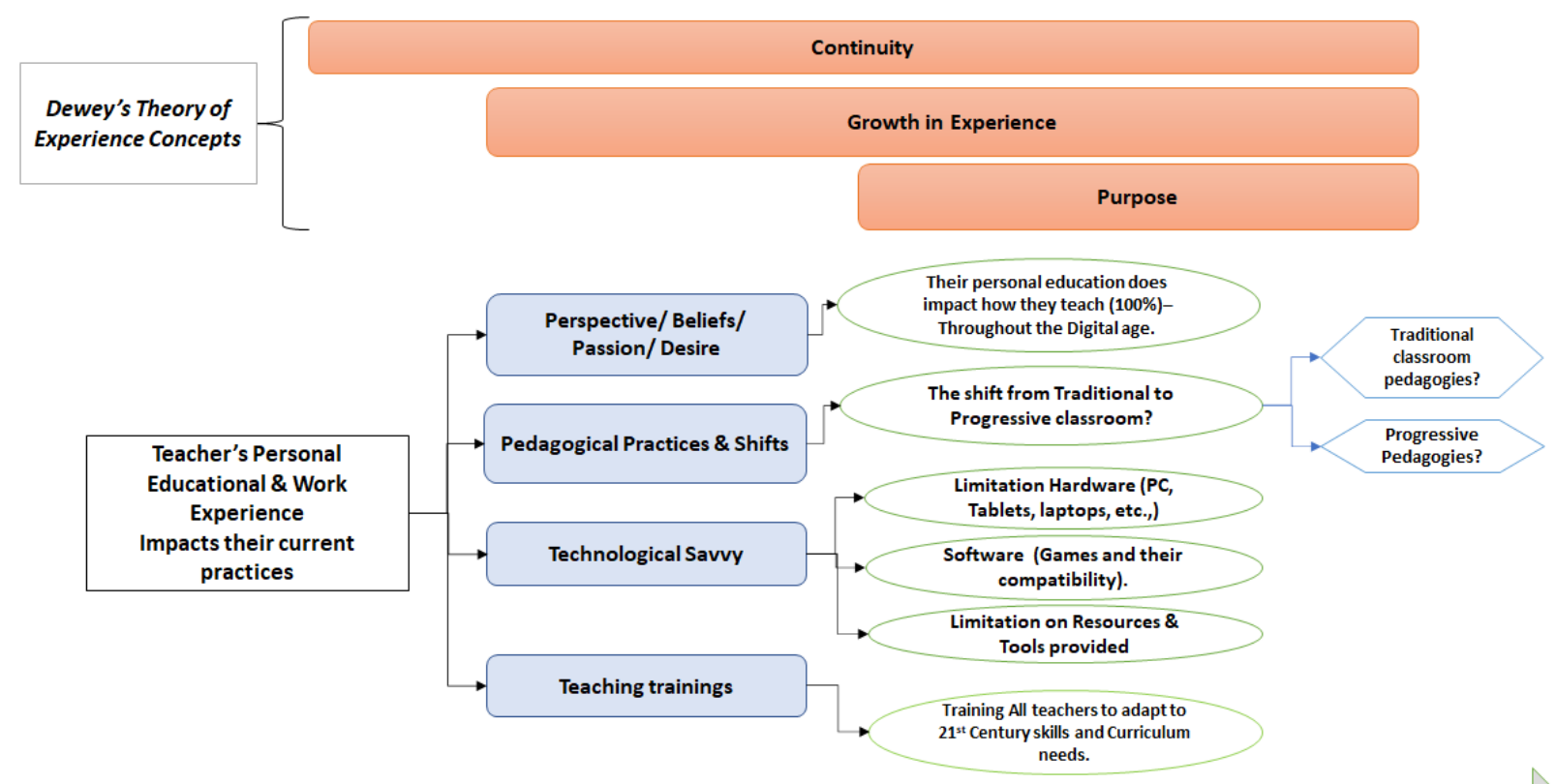

Experience of primary school teachers for $10+$ years in teaching practices

*' Growth in experience,' 'continuation of learning, debriefing and accumulating knowledge,' and 'purpose' are applied due to the need of repurposing the task through pedagogies and teaching practices.

As an educator with over nine years of higher education experience (despite its differences with primary education), the changes in pedagogies over the years to accommodate the learning process for students, accommodate their needs, ensure they gain knowledge, provide guidelines, and be aware of the current technologies used to provide realistic experience is growing. The pandemic has made it challenging for all educators and students. The difficulties that impacted the education systems, emphasizing developing higher-order thinking and problem-solving skills through distance learning, are nearly unachievable. The information apocalypse era and the reach of information at our fingertips have both strengths and weaknesses.

\section{CONCLUSION}

Teachers' personal education and work experience is an accumulated source of skills, knowledge, and practices that they acquire to contribute towards their current reforming teaching practices. Individual experiences of primary school teachers contribute to their daily routines of decision-making processes and which teaching method (pedagogies) should be used to deliver the learning outcomes of the subject being taught. It is crucial to understand teachers' experiences as it provides a continuous form of learning, gaining knowledge, and delivering knowledge to children (younger generation) with pedagogical approaches that are not entirely identical to how teachers themselves were taught in the 80s or 90s. Their desire to achieve 'satisfaction' in delivering learning is connected to their personal inspirational and motivational drivers. The addressing of pedagogical shifts, their technological 'savvy' skills, and the teaching pieces of training impacts the way they experience learning. Continuous growth through experience in their own education somewhat enforces their abilities to be able to deliver learning more interactively. To conclude, I believe 
that this paper contributes to the body of knowledge of teachers' perspectives, their roles in the classroom, and their crucial position of being an educator to young learners.

There were some limitations in the current study, including a reduction of participants' number due to the pandemic (2020), the number of words to represent the complete analysis, and the scope of recruitment changes. The data collection procedures began with pandemic lockdown (March 2020), which enforced reexamining the number of participants from initial anticipation (30 teachers) to 15 teachers. The decrement achieved saturation in data analysis procedures; hence, 11 teachers provided in-depth data. Furthermore, the research project timeline also ensured all data collection methods were completed within a period. Despite that, the generalization may still apply in Australia's context. The teachers presented in the current analysis may only be beneficial for primary level teachers as the types of tools, resources, and curriculum and its relevant practices may not be applicable for secondary or secondary higher education.

Future work is to conceptualize concepts/principles in the theory of experience (situation, intelligence, freedom) into the data analysis to expand teachers' experiential perspectives further. In addition, the author will be employing the primary school teachers' experience as case studies onto FrameTEP framework (Prestridge \& de Aldama, 2016) and enhance the usability of the framework and expand the use of the framework to allow versatility of the use of technology in the classroom. Currently, the FrameTEP framework advocates that it is based on technological use in the classroom. In contrast, the author would like to expand the framework by increasing a few emerging pedagogies yet to be informed in detail through semi-structured theoretically designed interviews.

\section{REFERENCES}

Appelman, R. (2005). Designing experiential modes: A key focus for immersive learning environments. TechTrends, 49(3), 64-74.

Beavis, C., Dezuanni, M., \& O’Mara, J. (2017). Serious play: Literacy, learning and digital games. Taylor \& Francis.

Beavis, C., Rowan, L., Dezuanni, M., McGillivray, C., O’Mara, J., Prestridge, S., . . Zagami, J. (2014). Teachers' beliefs about the possibilities and limitations of digital games in classrooms. $E$ learning and Digital Media, 11(6), 569-581. doi: 10.2304/elea.2014.11.6.569

Bigum, C. (2014). Thinking beyond massive, open and online programmed instruction.

Braun, V., \& Clarke, V. (2006). Using thematic analysis in psychology. Qualitative Research in Psychology, 3(2), 77-101.

Braun, V., \& Clarke, V. (2012). Thematic analysis.

Crawford, C. (1984). The art of computer game design.

Dewey, J. (1938). Experience and education: Kappa Delta Pi (First Touchstrone Edition 1997 ed. Vol. 1998). Rochefeller Center, New York, NY 10020: Touchstone NY.

Gee, J.P. (2003). What video games have to teach us about learning and literacy. Computers in Entertainment (CIE), 1(1), 20-20.

Kafle, N.P. (2011). Hermeneutic phenomenological research method simplified. Bodhi: An Interdisciplinary Journal, 5(1), 181-200.

Kebritchi, M. (2008). Examining the pedagogical foundations of modern educational computer games. Computers \& Education, 51(4), 1729-1743.

Knowles, M.S. (1980). From pedagogy to andragogy. Religious Education.

Knowles, M.S., Holton, E.F., III, Swanson, R.A., \& Robinson, P.A. (2020). The adult learner: The definitive classic in adult education and human resource development.

Kolb, D.A. (1984). Experiential Learning: Experience as the Source of Learning and Development. Prentice Hall.

Könings, K.D., Seidel, T., Brand-Gruwel, S., \& van Merriënboer, J.J. (2014). Differences between students' and teachers' perceptions of education: Profiles to describe congruence and friction. Instructional Science, 42(1), 11-30. 
Maass, K. (2011). How can teachers' beliefs affect their professional development? ZDM, 43(4), 573586.

Merleau-Ponty, M., \& Smith, C. (1962). Phenomenology of perception (Vol. 2012). Routledge London. Mezirow, J. (1990a). Fostering critical reflection in adulthood. Jossey-Bass Publishers San Francisco.

Mezirow, J. (1990b). How critical reflection triggers transformative learning. Fostering Critical Reflection in Adulthood, 1(20), 1-6.

Prestridge, S., \& de Aldama, C. (2016). A classification framework for exploring technology-enabled practice-FrameTEP. Journal of Educational Computing Research, 54(7), 901-921.

Razak, A.A., Connolly, T., \& Hainey, T. (2012). Teachers' views on the approach of digital games-based learning within the curriculum for excellence. International Journal of Game-Based Learning (IJGBL), 2(1), 33-51.

Salen, K., \& Zimmerman, E. (2004). Rules of play: Game design fundamentals. MIT press.

Schoenfeld, A.H. (2015). How we think: A theory of human decision-making, with a focus on teaching. Paper presented at the The proceedings of the 12th international congress on mathematical education.

Skott, J. (2001). The emerging practices of a novice teacher: The roles of his school mathematics images. Journal of Mathematics Teacher Education, 4(1), 3-28.

Stipek, D.J., Givvin, K.B., Salmon, J.M., \& MacGyvers, V.L. (2001). Teachers' beliefs and practices related to mathematics instruction. Teaching and Teacher Education, 17(2), 213-226.

Van Manen, M. (2016). Researching lived experience: Human science for an action sensitive pedagogy. Routledge.

Varea, V., \& Ndhlovu, S. (2017). Primary school games and play as inclusive/exclusive situations. Ágora para la Educación Física y el Deporte, 19(2-3), 158-176. 